\title{
O PECADO COMO FORMA DE REDENÇÃO: \\ UMA ANÁLISE DA INFLUÊNCIA DA LITERATURA \\ DE DOSTOIÉVSKI NA OBRA DE LÚCIO CARDOSO
}

Nelson Ricardo Guedes dos Reis*

RESUMO:

Dostoiévski foi uma das principais referências literárias de Lúcio Cardoso. Suas personagens, assim como as do autor russo, buscam no pecado a salvação. Na obra desses dois autores, o homem só atinge a redenção pela danação. É através do pecado que suas personagens chegam a Deus.

PALAVRAS-CHAVE: pecado, redenção, danação, salvação, transgressão.

0 homem e os estados intimos do ser são as principais temáticas da literatura dostoievskiana. Há mais de cinqüenta anos atrás, o crítico literário Wilson Martins assim definiu a obra de Dostoiévski:

"Cuidando essencialmente do homem e da finalidade de sua existência sobre a terra, procurando desvendar os motivos e as conseqüências ocultas de todos os nossos atos, ansiando perpetuamente por resolver o secular problema do determinismo e do livre arbitrio, fundamentando toda a sua obra na discussão metafísica do problema da liberdade - interessando, pois, pelo homem, e por ele somente, Dostoiévski fundou uma antropologia que é, antes de tudo, uma gnose. (...) Suas pesquisas exclusivas dirigiam-se sempre para 0 homem, revolvido nos abismos esconsos de seu espírito, num romance em que o Cristo está sempre presente, mesmo quando nem o seu nome nem a sua idéia são pressentidos." (Martins, 1962: XIII).

Lúcio Cardoso, que já chegou a ser comparado, de forma um tanto quanto precipitada, ao escritor de Crime e castigo, ${ }^{1}$ nunca procurou esconder a determinante influência que teve o escritor russo na concepção de sua obra ficcional. Em uma entrevista concedida a Fausto Cunha, Lúcio aponta algumas características da literatura de Dostoiévski apropriadas por ele e por outros escritores de sua geração:

* Mestre em Letras: Estudos Literários (Área de concentração: Teoria da Literatura), 2002. 


\title{
EM TESE
}

Belo Horizonte, v. 7, p. I-I I0, dez. 2003

\begin{abstract}
"Esse homem subterrâneo, esse atormentado e de alma nua que tanto nos horripila às vezes, é exatamente o continuador dos romances clássicos que 0 século passado nos transmitiu: a época nova, inaugurada com os intermináveis monólogos de Dostoiévski, prosseguiu através da voz precursora de alguns filósofos até arrebentar nessa figura de hoje, que tantos escritores de talento procuram observar e conduzir às suas peças de teatro, aos seus romances e novelas." (Cardoso, 1997: 761).
\end{abstract}

Assim como as personagens dostoievskianas, as personagens de Lúcio Cardoso buscam, no pecado, a salvação. Só através do pecado o homem pode alcançar Deus. Falando da literatura de Lúcio Cardoso, Octávio de Faria nos diz:

"É de dentro dessa concepção eminentemente trágica de um universo 'prometido ao sofrimento' e 'abandonado pela graça', de onde a esperança parece estar sendo constantemente escorraçada a golpes de maldade e egoísmo, de traição e de desamor, que o autor faz surgir os seus personagens." (Faria, 1997: 660).

Em Lúcio Cardoso, somente após o homem atingir o ápice do desespero, ao se sentir só, sem esperança e sem luz, ou seja, quando alcançar o fundo do abismo existencial, somente nesse momento ele poderá encontrar a luz e a redenção, como acontece com Job, a personagem bíblica. E não é surpresa nem coincidência o fato de Lúcio ter traduzido o Livro de Job para a Editora José 0lympio, em 1943. As principais personagens de Lúcio Cardoso são jobianas, personagens que descem ao fundo do abismo existencial para lá encontrar a luz, pois é só através da tragédia e da desgraça que elas encontram a salvação.

As personagens cardosianas, destituídas de fé e habitando um mundo sem Deus, ${ }^{2}$ buscam a salvação através da danação. Segundo Padre Justino, uma das personagens de Crônica da casa assassinada: "(...) grande pecado maior de não ousar o supremo pecado, para se constituir humano e só, e divisar a face una e resplandecente, no abismo oposto, que é feito de luz e de perdão!" (Crônica..., p. 568). Interpretando as palavras de Padre Justino: para se constituir humano, o homem deve ousar o supremo pecado; só através do pecado, da danação, ele pode divisar a face resplandecente que é o perdão, e, conseqüentemente, a salvação. A consciência religiosa, baseada na dor e no sofrimento, é purificadora. É essa consciência que impulsiona as personagens cardosianas por caminhos repletos de vícios, para que no final encontrem a salvação pela via do pecado e do sofrimento. Nelly Novaes Coelho assim descreve as personagens de Lúcio Cardoso: 
"Quem são afinal, as criaturas que encontramos nesse mundo, caminhando por entre 'a massa espessa das horas', sob a 'sensação sufocante da atmosfera'? Personagens torturados, ilhados pela incomunicabilidade e pela ausência de Deus. Mesclando densa estagnação vital do 'espaço' provinciano em que se arrastam os personagens, o pecado da carne é uma presença quase corpórea." (Coelho, 1997: 777).

Devido à impossibilidade de encontrar Deus pelas vias ortodoxas, ditas normais, o homem cardosiano procura o pecado e a danação. Segundo Novaes Coelho: "Incapaz de atingir a beatificação dos santos ele assume o demoníaco dos humanos (...)" (Coelho, 1997: 776). Nabokov costumava dizer que as personagens dostoievskianas abriam caminho em direção a Deus através de golpes de pecado. 0 mesmo poderia ser dito em relação às personagens cardosianas. 0 próprio Octávio de Faria, em trecho já reproduzido anteriormente, disse em relação ao universo literário de Lúcio Cardoso que, neste, a esperança parece estar sendo constantemente escorraçada a golpes de maldade, confirmando que em Lúcio, assim como em Dostoiévski, é através da danação que o homem atinge a salvação. Citando mais uma vez Novaes Coelho: "(...) uma dolorosa busca de Deus, exatamente naquilo que, aos olhos dos homens e da tradição, não é Deus" (Coelho, 1997: 779).

Essa comunhão com Deus através do pecado é fartamente encontrada na obra de Dostoiévski, em Crime e castigo, por exemplo, onde percebemos claramente a presença da tríade dostoievskiana: Pecado-Perdão/Punição-Salvação. Neste romance, a personagem Raskólnikov peca ao cometer um assassinato, e busca neste pecado a solução para seus tormentos íntimos e seu vazio interior. A personagem percorre um longo caminho de danação, buscando uma punição ao se arrepender de seu ato. E, finalmente, atinge a salvação ao ser castigado. Wilson Martins, em texto já citado, vê da seguinte forma o drama de Raskólnikov:

"Dentro do estudante que mata a velha repugnante e usurária instala-se 0 tribunal que deve julgá-10 e que o obriga, afinal, a entregar-se à justiça dos homens - que, condenando-o à Sibéria, prendendo-o portanto, dão-1he a maior liberdade de sua vida, porque lhe oferecem a possibilidade de expiação, de reconciliação com o Cristo, com a verdade." (Martins, 1962: XIV).

A personagem chega a Deus pelo tortuoso caminho da danação. Este mesmo percurso é realizado por várias personagens cardosianas: personagens transgressoras. Para Bataille: 


\section{EM TESE}

Belo Horizonte, v. 7, p. I-I I0, dez. 2003

"A transgressão teria revelado o que o cristianismo encobriu: que é 0 sagrado e 0 interdito se misturando, que 0 acesso ao sagrado se faz através da violência de uma infração. (...) 0 acesso ao sagrado é 0 mal; ao mesmo tempo o mal é o profano." (Bataille, 1989: 181).

Nas literaturas de Dostoiévski e Lúcio Cardoso, o pecado, o mal, o inferno e o demônio têm uma conotação positiva. Esses elementos representam a transgressão, que, na concepção religiosa desses dois autores, é uma forma de se chegar ao sagrado: aqui, o sagrado e o profano caminham lado a lado. Personagens como Ida, de Mãos vazias; Madalena, de A luz no subsolo; Inácio, de Inácio e 0 enfeitiçado; Nina e Ana, de Crônica da casa assassinada; Donana de Lara, de 0 viajante, dentre outros, procuram no pecado a salvação: Ida, traindo o marido um dia após a morte do filho; Madalena, envenenando o marido; Inácio, deflorando Adélia enquanto esta se encontrava em estado de semi-inconsciência; Nina, deixando que André acreditasse que estava dormindo com sua própria mãe; Ana, renegando o próprio filho; e, finalmente, Donana de Lara, assassinando o filho inválido. Todas essas personagens buscam, através dessas ações aparentemente ilógicas e absurdas, uma solução para seus tormentos, para seu vazio interior, para uma angústia inominável. Essa solução, em Lúcio Cardoso, e claro, em Dostoiévski, está em Deus e na redenção.

Para Nelly Novaes Coelho: "É assumindo a danação que elas, as personagens de Lúcio, afirmam a grandeza de sua condição humana frente a Deus, naquele sentido profundo já revelado pelas personagens de Dostoiévski: ...é porque erro que sou humano" (Coelho, 1997: 783). Em uma passagem de Crônica da casa assassinada, a personagem Ana pergunta ao Padre Justino, em tom de confissão, e como que exigindo a absolvição: "Padre, e eu, não estou salva também, não pequei como os outros, não existi?" (Crônica..., p. 577).

Somos levados a acreditar, motivados pelas evidências, que Lúcio buscou realizar em sua obra parte de suas convicções filosóficas e teológicas. Não podemos deixar de ver, na frase abaixo, uma espécie de pedra fundamental de suas principais obras: "Somente a prática de uma falta grave desencadeia as tremendas forças de remorsos requeridos pela verdadeira conversão religiosa." (Diário completo, p.78).

De todas as personagens cardosianas que abrem caminho em direção a Deus a golpes de pecados, sem dúvida uma das mais emblemáticas é Inácio, personagem da 
novela Inácio (1944) e protagonista da novela 0 enfeitiçado (1954). Não é por acaso que Lúcio batizou de 0 mundo sem Deus a trilogia de que fazem parte Inácio e 0 enfeitiçado, e que teria em Balthazar (inacabado) sua conclusão. Inácio é o protótipo das personagens cardosianas: atormentado, angustiado, tomado de um grande vazio interior e de uma profunda inquietude existencial, e que, após toda uma vida afastado de Deus, busca encontrá-10 no pecado. Para as personagens de Lúcio Cardoso, como bem observou Nelly Novaes Coelho: "0 mal foi o elemento que afastara o homem de Deus e da verdadeira vida. 0 mal deveria ser o elemento que novamente os reaproximaria" (Coelho, 1997: 777). E mais à frente conclui que, em 0 enfeitiçado, Lúcio adota, assim como em Inácio, o foco narrativo em primeira pessoa: "(..) fundido portanto personagem e narrador. Assim, em Inácio Palma temos pela primeira vez uma ação que adquire realmente uma dimensão 'Demoníaca', no sentido da imersão consciente no erro, no pecado." (Coelho, 1997: 779)

É exatamente essa imersão consciente no pecado, citada por Nelly Novaes Coelho, que aproxima as personagens criadas por Lúcio Cardoso das personagens dostoievskianas. Nos dois autores percebemos a convicção de que, se o pecado havia afastado Deus do homem, só o pecado poderia reaproximá-los, pois, segundo as palavras de uma das personagens de Crônica da casa assassinada:

"Decerto o problema supremo é este: Deus e o homem, mas por mais que faça, não posso imaginar Deus afastado do amor, de qualquer amor que seja, - mesmo o mais pecaminoso - (grifo nosso), porque não posso imaginar o homem sem amor, e nem o homem sem Deus." (Crônica..., p. 325).

Em 0 enfeitiçado, após perceber que havia perdido Rogério, seu filho, de forma irremediável, Inácio vê em Adélia de Val Flor - uma adolescente que de certa forma The tinha sido "vendida" pela própria mãe, a cartomante Lina de Val Flor - sua última esperança de redenção. Ele sabia que tinha fracassado ao "moldar sua personalidade com a bruta força de seu egoísmo e de sua indiferença" ( 0 enfeitiçado, p.306). Mas, onde havia fracassado? Não vivera como sempre desejara? Uma vida de pecado, afastado de Deus e do amor? Contudo, no final da vida, na velhice, busca reencontrar os dois: Deus e o amor, através da família, a nova família que pretende construir ao lado de Adélia. Nessa novela, Lúcio se apóia na tríade cristã: Deus, Amor e Família, sem as quais o homem burguês se encontra à deriva, perdido em si 


\section{EM TESE}

Belo Horizonte, v. 7, p. I-I I0, dez. 2003

mesmo. Porém, a forma que Inácio encontra para se aproximar de Deus é mais uma vez o pecado, esse mesmo pecado que o havia afastado de Deus e que agora deveria reaproximá-los. Ao embebedar Adélia e deflorá-la sem seu consentimento, Inácio procura no mal e no pecado sua salvação. Adélia, que Inácio via como sua redenção - "Não suportava mais o vazio e a indiferença com que vivera até aquela época" ( 0 enfeitiçado, p. 307) -, viria a ser a responsável por sua derradeira destruição. Antes de começar a narrar a noite em que embebeda Adélia e a leva para seu quarto, Inácio escreve:

"Começa aqui a minha destruição. Não temam, não recuem diante da palavra, pois ela serve apenas para exprimir o sistema de desintegração que foi 0 meu, tão idêntico em suas linhas essenciais a todos os processos de falência e morte que a humanidade conhece." (0 enfeitiçado, p. 318).

No restaurante, com Adélia, Inácio é acometido de um riso alucinado e extasiante, o mesmo riso que dominou Rogério na última página da novela Inácio, um riso libertador:

"Daquela vertigem que me tomara à rampa do cais do porto, julguei poder renascer forte e vivo. Talvez pudesse salvar tudo - talvez -, e eu comecei a rir como antigamente, um riso rouco e feroz, sentindo abalar-se toda a estrutura do meu ser. Ria como poucas vezes rira naqueles últimos anos, totalmente, sentindo que as lágrimas me vinham aos olhos. (...) e confesso que tremia, tremia da cabeça aos pés, vislumbrando não sei que misteriosa saída àquele túnel que eu penetrara." (0 enfeitiçado, p. 319).

Para Inácio, Adélia era sua esperança de um renascer forte e vivo, a saída do túnel que penetrara metro a metro durante toda sua vida. Ainda no restaurante, Inácio é tomado pelo mal: "Não sei também em que momento a diabólica idéia se apossou de mim" (0 enfeitiçado, p. 318). Após embebedar Adélia, Inácio a leva para o seu quarto em uma dessas pensões que "(...) abundam nos subúrbios, sem espaço, sem conforto, sem nenhuma tranqüilidade ou repouso" (0 enfeitiçado, p. 275). A cena em que o protagonista deflora Adélia é repleta de significações. Sob uma atmosfera expressionista, o anjo da pureza é dominado pela vileza de Inácio, que momentos antes é tomado por um grande vazio, o qual, porém, não o impede de concretizar seu derradeiro pecado:

\footnotetext{
"Um grande vazio se fez entorno, só o meu coração, enorme, batia descompassado no meu peito. Tive a impressão de que outra força me conduzia e me fazia agir, independente da minha vontade. (...) e confesso que não tive nenhum pudor, nenhum remorso em profanar aquele corpo de criança." (0 enfeitiçado, p. 325).
} 
A partir desse momento, seu processo de destruição se acelera. Adélia o repele quando acorda e descobre o que aconteceu.

0 ciclo de Inácio se fecha. Agora, parafraseando Barbey D'Aurevilly - em comentário sobre o livro Às avessas, de J. K. Huysmans -, só havia dois caminhos para a personagem: "A boca de uma pistola ou os pés de uma cruz" (Huysmans, 1987: 273). As personagens de Lúcio Cardoso, assim como as de Dostoiévski, são o oposto da carolice: jamais se atirariam aos pés de uma cruz. Entre a cruz e a espada, sem dúvida a espada; entre o bem e o mal, o mal; entre o amor e o pecado, o pecado. É bastante significativa a cena final da história: o capanga de Lina de Val Flor (responsável por cobrar a dívida de Inácio, pois Adélia the foi "vendida", não doada) pendura uma forca no quarto de Inácio e se planta na portaria de seu prédio, inibindo sua fuga. Já que o direito de recomeçar lhe havia sido negado - através da repugnância de Adélia -, o caminho da cruz estava para sempre fechado. Só the restava, então, a forca.

Após a saída de Adélia, Inácio entra em um estado de delírio, não distinguindo mais o real do imaginário. Ao se olhar no espelho, vê o príncipe das trevas, Inácio não existe mais:

"0 espelho se achava não muito distante, e a luz acidentada, que vinha através da vidraça, era suficiente para me auxiliar naquele exame. Debruceime - e então eu o reconheci, sem estremecimento, sem terror, sem nada que perturbasse o reconhecimento, que agora fazia. (...) Lá estava ele, finalmente, modelado ao longo de tantos anos de crueza e impiedade, o deus que em vão eu procurara, que julgara transmitir ao meu filho, que vivera em todos os segundos do meu pensamento, que substituíra a minha força de vontade, que me acompanhara cega e devotamente, o grande anjo escuro e terrivel. (...) Não era eu, não era Inácio Palma, era ele, vociferante e negro, com rugas talhadas a limo e a fel, com os olhos marcados de pranto e de insuspeitadas vinditas, aperfeiçoado talhe a talhe, com sabedoria e conhecimento, durante todos os minutos em que me envenenara." (0 enfeitiçado, p. 336-7).

Não podemos nos esquecer de que, em Dostoiévski e Lúcio Cardoso, o mesmo Deus que criou o bem, criou o mal; o mesmo Deus que criou o amor, criou o pecado e - Diabo. Sendo assim, Deus também está no Diabo e no mal. Como bem disse Walter Benjamin: "0 Deus de Dostoiévski não criou apenas o céu e a terra e o homem e o animal, mas também a vingança, a mesquinharia, a crueldade. E também aqui o Diabo não interferiu com o trabalho" (Benjamin, 1985: 30-31). 


\section{EMTESE}

Belo Horizonte, v. 7, p. I-I I 0, dez. 2003

Em seus últimos momentos, Inácio é invadido pelo anjo do desastre, cuja voz ele ouve, exigindo seu lugar de direito, querendo sua total liberdade. As últimas palavras de Inácio são para Rogério, concluindo que não tinha existido até aquele momento: "Se o mundo existe, Rogério, não sou um espectro, a minha negação está de pé. Mas se o universo tiver apenas a profundeza de um sonho, então é injustificável que eu tenha vivido tanto." (0 enfeitiçado, p. 349). Frase ambígua, mas que nos faz acreditar que Inácio ainda luta, em seus últimos instantes, para justificar seu desprezo pelo homem e sua vida sem Deus.

Apesar de as personagem cardosianas buscarem a salvação no pecado, este, em Lúcio Cardoso, ao contrário do que acontece na obra dostoievskiana, pode destruir o homem. Vejam essa passagem de Crônica da casa assassinada, em que Timóteo, conversando com Betty, se recorda de uma palestra com Padre Justino:

"Um dia, no jardim, disse-me que quase sempre o pecado é coisa infima, um grão de areia, um nada - mas que pode destruir a alma inteira. Ah, Betty, a alma é uma coisa forte, uma força que não se vê, indestrutível. Se uma minúscula parcela de pecado - um nada, um sonho, um desejo mau - pode destruí-la, que não fará uma dose maciça de veneno, uma culpa instilada gota a gota no coração que quer se destruir." (Crônica..., p. 139).

Em Lúcio Cardoso, as personagens não encontram a paz, a salvação, pelo menos não neste mundo. Seu fim é quase sempre trágico. 0 que fica é um vazio, uma desesperança, uma profunda sensação de ausência. As personagens cardosianas procuravam, mas Lúcio não permitia que encontrassem, a salvação no pecado.

NOTAS:

1. Adonias Filho, em um ensaio publicado no "Caderno da Hora Presente", afirmou em relação às obras de Lúcio Cardoso publicadas até 1939, em especial a A luz no subsolo e Mãos vazias: "Devemos explicar porque recusamos, para eles, as denominações emprestadas aos livros de Dostoiévski. (...) Em verdade, recusamos porque os romances de Lúcio Cardoso, sem uma única exceção, são livros de classe superior."

2. Lúcio havia planejado uma trilogia intitulada 0 mundo sem Deus, composta das novelas Inácio, 0 enfeitiçado e Balthazar (inacabada). 
ABSTRACT :

Dostoiévski was one of the main literary references for Lúcio Cardoso. His characters, as well as those of the Russian author, seek salvation in sin. In these two authors' works, man will only reach redemption through damage. It is through sin that their characters reach God.

KEY WORDS: sin, redemption, damnation, salvation, transgression.

REFERÊNCIAS BIBLIOGRÁFICAS

BATAILLE, George. A literatura e o mal. Trad. Suely Bastos. Porto Alegre: L\&PM, 1989.

BENJAMIN, W. Obras escolhidas. Vol. I: Magia e técnica, arte e politica. São Paulo: Editora Brasiliense, 1985.

CARDOS0, Lúcio. Crônica da casa assassinada. Ed. crítica coordenada por Mario Carelli. Madrid, 1997.

- Três historias da cidade. (Inácio, 0 anfiteatro e 0 enfeitiçado). 2. ed. Prefácio de Marcos Konder Reis. Rio de Janeiro: Edições Bloch, 1969.

COELHO, Nelly Novaes. Lúcio Cardoso e a inquietude existencial. In: CARDOSO, Lúcio. Crônica da casa assassinada. Edição crítica coordenada por Mario Carelli. Madrid, 1997.

DOSTOIÉVSKI, F. Crime e Castigo. Rio de Janeiro: José 01 ympio, 1952.

FARIA, 0ctávio. Lúcio Cardoso, In: CARDoso, Lúcio. Crônica da casa assassinada. Edição crítica coordenada por Mario Carelli. Madrid, 1997.

HUYSMANS, J. K. Às avessas. São Paulo: Companhia da Letras, 1987.

MARTINS, Wilson. Dostoiévski como romancista. In: DOSTOIÉVSKI, F. 0 eterno marido e outras novelas. Rio de Janeiro: José 0lympio, 1962. 